\title{
INTEGRATING FACEBOOK AND ALUMNI INTO THE SOCIAL NETWORK MOBILE PLATFORM
}

\author{
Tzuo-Ming Chen \\ Shih Chien University \\ 200 University Road Neimen, Kaohsiung 84550 Taiwan, R.O.C. \\ jchen@mail.kh.usc.edu.tw \\ Chi-Tsai Yeh \\ Shih Chien University \\ 200 University Road Neimen, Kaohsiung 84550 Taiwan, R.O.C. \\ yehchitsai@mail.kh.usc.edu.tw
}

\begin{abstract}
Social network systems have become one of the most popular Internet applications in recent years. Mobile devices such as smartphones and tablets make Internet access easier than ever before. They have also brought new opportunities for the social platforms of universities and their alumni. This paper proposes a mobile platform integrating the public social network site, facebook (FB), and universities' alumni. Before the users in this platform can contact the alumni, they must know their latest status from FB. Users can also gain alumni's personal information with their authorization from the universities' database. In addition, the mobile platform utilizes the Google Sync feature, which provides users of the system with ubiquitous information retrieval in any location and from any device.
\end{abstract}

Keywords: Smart Mobile Devices, Social Network Sites, Google Sync

\section{INTRODUCTION}

Alumni are key resources for universities. However, alumni management is a heavy task with huge manpower consumption and communication costs. How to gain alumni information such as current phone number, employment status, current marriage, etc., is another challenge. Social network sites (SNSs) such as Facebook (FB), LinkedIn, and MySpace allow individuals to present themselves, articulate their social networks, and establish or maintain connections among their favorite communities with efficiency, low-cost, and in-time ${ }^{1,2}$. According to official 
FB statistics ${ }^{3}$, the number of FB users in the world has exceeded 900 million as of September 2012. In addition, more than one million developers and entrepreneurs from more than 180 countries are developing applications based on the FB platform. Currently, more than 550,000 applications are active on the platform.

The term "virtual community" was first proposed by Howard Rheingold ${ }^{4}$ in 1993. In Web 2.0 era, most of the virtual communities have been changing their ways of management from emphasizing managing personnel and obvious encouragement to emphasizing user and influencing user's willing ${ }^{5}$. SNS refers to a system with completely or partially accessible individual information ${ }^{6}$ which can be shared with other members. When a person joins an SNS, the system will prompt other relevant users. Furthermore, SNS allows users to send messages publicly or privately.

Kang et al. $^{7}$ note that enjoyment is the most important factor in use of FB. In addition, it also affects users' behavior. The user can share pictures, movies, their personal status, and interesting links. These services provide entertainment for users and their friends ${ }^{8}$.

Many SNSs have begun providing service on smartphones. Social networks ranked second in application utilization rates, reaching $32 \%$ in Flurry's 2011 survey ${ }^{9}$.

This paper establishes an efficient social network platform using mobile handheld devices that provides up-to-date information on the alumni community. This mobile platform collects users' FB information and allows alumni to keep in touch. The next section of the paper discusses the proposed mobile platform. The third section presents the result of the experiment. The final section makes conclusions.

\section{PROPOSED MOBILE PLATFORM}

As shown in Figure 1, the smartphones communicates FB, universities, and Google Apps through a variety of application program interfaces (APIs) such as FB for Android ${ }^{10}$, hypertext transfer protocol (HTTP), and Google contact. The platform utilities the FB API to login to FB, to retrieve friends' name lists, to setup the access permission, and so on. Universities provide a specific web service for platform developers. The web service contains alumni authorization, individual data modification, data retrieval, and permission control. The web service supports security and flexibility. The designers do not know the structure of the university alumni system but gain the required data. Google Sync allows the platform to replicate the alumni data into the Google Apps domain. 


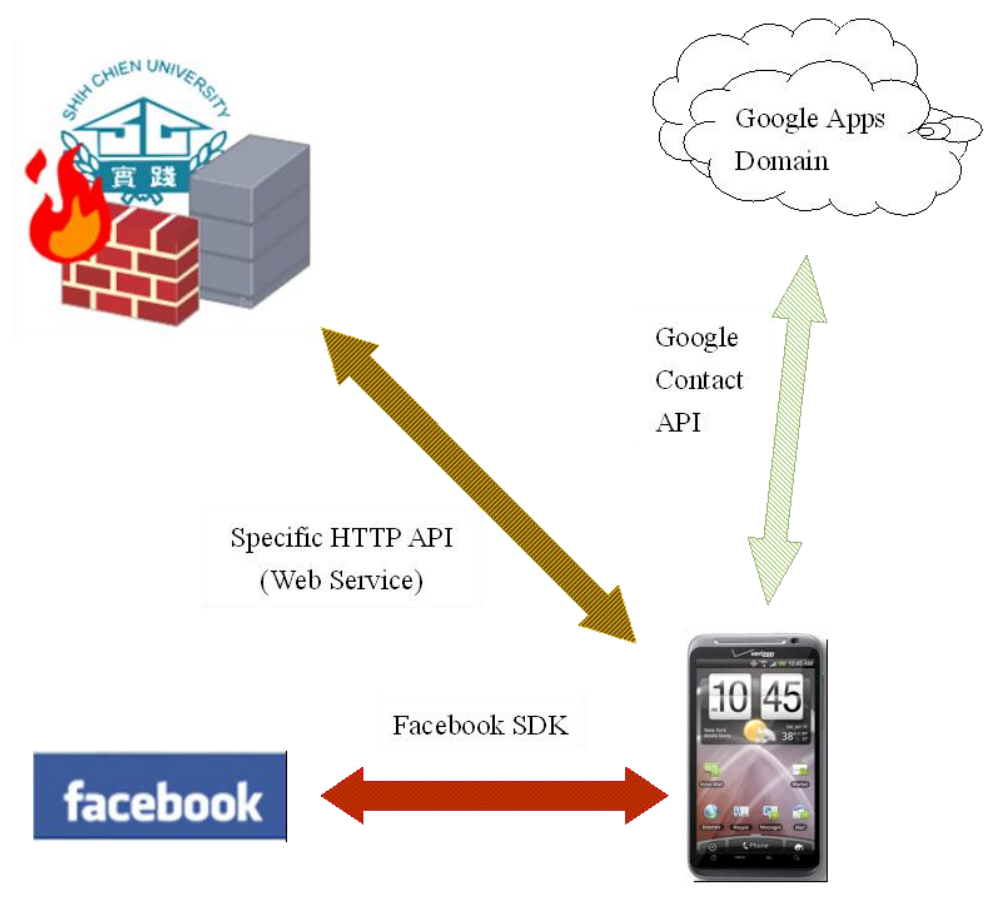

Figure 1. The deployment of social network mobile platform

Figure 2 shows the relationship between the FB community and the alumni community. The proposed mobile platform combines the alumni into FB as shown in the intersection of Figure 2. Once the user signs in to the mobile platform, it implies that he/she is both a FB member and alumnus. FB Fan, Google+, and LinkedIn all focus on public domains instead of private domains. Our alumni community is a private community limited to invited members only. The intersection includes the following categories:

- Good friends: these are both FB friends and alumni. The platform retrieves data of the alumni and FB friends from the university alumni system and FB, respectively, and adds the result of the intersection into the list of good friends. Meanwhile, the user requests permission by e-mail to obtain personal information of good friends. For privacy reasons, this information cannot be accessed on the university alumni system until approval has been received.

- Others: if one person is within the alumni community but not in the user's FB friends list, then the platform will categorize this person into the others list. The user can submit an invitation email to ask others to become FB friends. After receiving a positive response, the platform will move this friend to the list of good friends. 


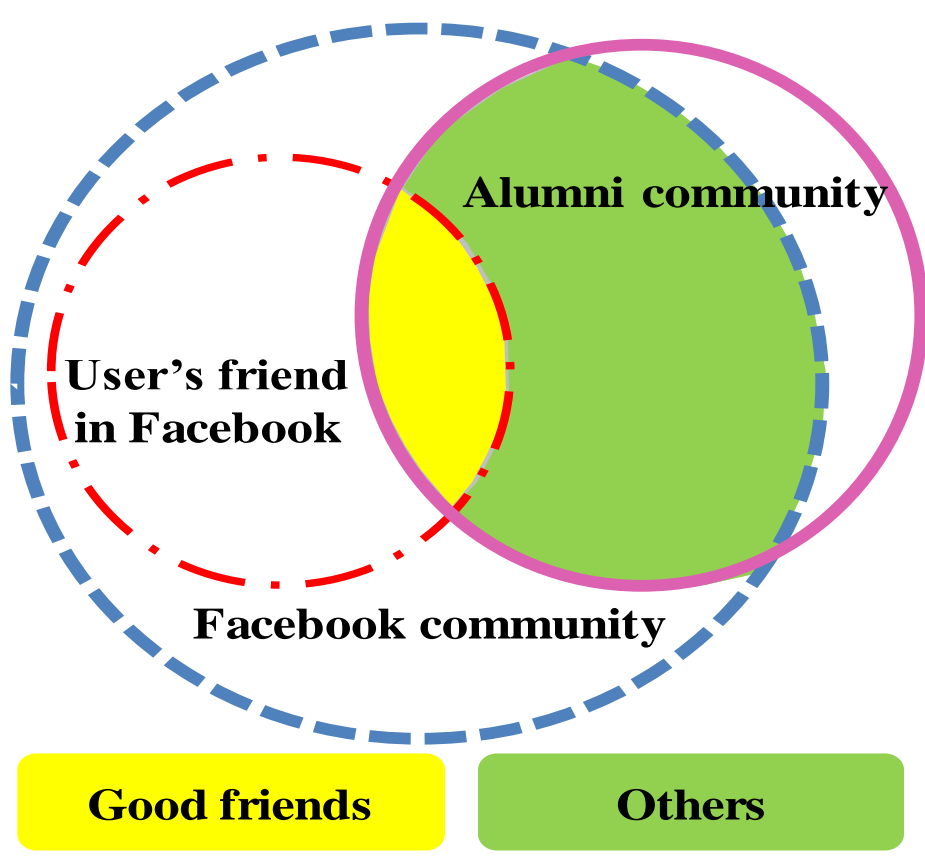

Figure 2. The relationship between FB and alumni community

\section{PROTOTYPE DEMONSTRATION}

The prototype platform has been designed and packed as an 'apk' android installation file for validation and verification. The designers execute this application not only on smartphones but on the tablets with Android 2.3 and 3.2.

The functions of the platform are as follows:

1. Authorization: The user has two phase authorizations. The university alumni system validates the first account, and Facebook SNS checks the second account.

2. Permission access control: The university alumni system provides different permission access controls consisting of individual data modification and personal information retrieval of good friends.

3. List of community members: The platform allows the user to browse the lists of FB friends, good friends, and others.

4. Latest status: The refresh button updates the number of alumni, the number of the application users, the number of the FB friends of the current user, and the number of the current user's good friends separately.

5. Google Sync: The Android system periodically synchronizes the contact data on mobile platforms with Google contacts in the Google 
Apps domain. Therefore, this mobile platform can add or update good friends with detailed information into the contacts. This feature of allows the user to access alumni contacts from any device.

\section{CONCLUSION}

This paper demonstrates a prototyping structure of mobile platform for an academic social network that combines Facebook, the university alumni system, and Google Sync as the underlining infrastructures. This platform allows alumni to communicate conveniently and universities to automatically collect the latest alumni contact information. Alumni are the most important resources to the universities as they provide financial contributions for universities and can share experiences with younger alumni. The proposed platform makes communication more efficient. The functionalities have been verified on several mobile platforms; however, a monitoring and evaluation mechanism should be developed to guarantee that the goals are achieved in the future.

\section{ACKNOWLEDGMENT}

This work was supported by This work was supported by College of Business and Information, Shih Chien University under contracts USC-100-05-05013 and USC-101-05-05010.

\section{REFERENCES}

[1] N.B. Ellison, C. Steinfield, and C. Lampe, The benefits of Facebook "friends:" Social capital and college students' use of online social network sites. Journal of Computer-Mediated Communication, 12(4), p1143-1168, 2007. http://dx.doi.org/10.1111/j.1083-6101.2007.00367.x.

[2] D. Boydm, and B.N. Ellison, Social network sites: Definition, history, and scholarship. Journal of Computer-Mediated Communication, 13, 210-230, 2007. http://dx.doi.org/10.1111/j.1083-6101.2007.00393.x.

[3] Facebook Marketing Statistics, Demographics, reports, and news. Retrieved on September 30, 2012, from http://www.check facebook.com/.

[4] H. Rheingold, The virtual community: Finding connection in a computerized world. Retrieved on September 10, 2012, from http://www.rheingold.com/vc/book/.

[5] G. Deng, H. Zhou, and P. Zhang, Study of incentive mechanism and internet behavior of virtual communities. In T. Zhu, J. Yan, and Q. 
Zhou (Eds.), Proceedings of the 1st IEEE Symposium on Web Society (p213-218). Lanzhou, China: IEEE Press, 2009. http://dx.doi.org/10.1109/SWS.2009.5271797.

[6] D. Boyd, Why youth (heart) social network sites: The role of networked publics in teenage social life. Retrieved on September 10, 2012, from http://sjudmc.net/lyons/civicmedia1/wp-content/uploads/2013/09/boydWhy-teens-heart-social-media.pdf.

[7] S.Y. Kang, S.G. Hong, and H.S. Lee, Exploring continued online service usage behavior: The roles of self-image congruity and regret. Computers in Human Behavior, 25(1), p111-122, 2009. http://dx.doi.org/10.1016/j.chb.2008.07.009.

[8] J. Powell, 33 million people in the room: how to create, influence, and run a successful business with social networking. New Jersey: Financial Times Prentice Hall, 2009.

[9] C. Newark, Mobile apps put the web in their rear-view mirror, flurry blog. Retrieved on June 12, 2011, from http://blog.flurry.com/bid/63907/Mobile-Apps-Put-the-Web-in-Their-R ear-view-Mirror.

[10] GitHub Social Coding, Facebook SDK for Android, Retrieved on February 23, 2012, from https://github.com/facebook /facebook -android-sdk. 